\title{
O ensino e a produção da fotografia artística: - caso do curso FIC de extensão do IFPB
}

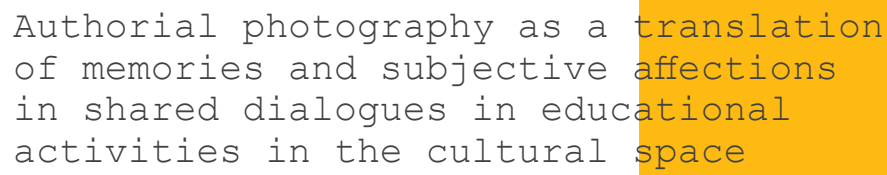

Hélder Paulo Cordeiro da Nóbrega ${ }^{1}$

1 Graduado em Cinema e Audiovisual (UFPB), aperfeiçoado em fotografia artística (IFPB), mestrando em Artes Visuais (PPGAV - UFPB /UFPE). Atua como fotógrafo artístico e diretor de arte para cinema.

Lattes: http://lattes.cnpq.br/1926911987569403

E-mail: heldercinema@gmail.com 


\title{
Resumo
}

O presente artigo trata do ensino e da produção da fotografia artística no estado da Paraíba. Tendo como recorte o curso FIC de extensão em fotografia artística do Instituto Federal de Educação, Ciência e Tecnologia da Paraíba - IFPB. Tal aperfeiçoamento é ofertado de forma gratuita, propiciando a acessibilidade de um público diversificado. A metodologia utilizada foi de um estudo de caso com uma pesquisa participante. $O$ texto explana acerca do tempo atual, sem perder de vista a historicidade do ensino, aprendizagem e fluidez da arte contemporânea paraibana, com enfoque no ensino e na produção da fotografia artística.

\section{Palavras-chave}

fotografia artística; artes visuais; cursos de extensão; ensino de fotografia.

\begin{abstract}
This article deals with the teaching and production of artistic photography in the state of Paraíba. Having as a cut the FIC extension course in artistic photography from the Federal Institute of Education, Science and Technology of Paraíba - IFPB. Such improvement is offered free of charge, providing access to a diverse audience. The methodology used was a case study with participant research. The text explains about the current time, without losing sight of the historicity of teaching, learning and fluidity of contemporary art in Paraíba, with a focus on teaching and production of artistic photography.
\end{abstract}

\section{Keywords}

artistic photography; visual arts; Extension courses; photography teaching. 


\section{Introdução}

Ao terminar a graduação em Cinema e Audiovisual na UFPB, no ano de 2016, sentimos a necessidade em continuar os estudos científicos que envolvessem o nosso desenvolvimento artístico e profissional. No início de 2017, objetivando obter uma maior aproximação acadêmica com as Artes Visuais ingressamos no Curso FIC de Extensão em Fotografia Artística do IFPB, campus João Pessoa, que ofertado de forma gratuita, tem duração de dois anos.

Para nós, enquanto discentes participantes, o curso passou a suprir uma carência em especialização na área da arte, na especificidade da fotografia, haja vista a inexistência de pós-graduações técnicas, no âmbito citado, no estado da Paraíba. Sendo assim, utilizando como metodologia, um estudo de caso com uma pesquisa participante verificando no curso aludido uma excelente oportunidade para quem deseja ingressar ou aprofundar seus estudos de natureza artística ou interessados em atuar na docência em fotografia.

Através da referida capacitação, obtivemos novos conhecimentos que dizem respeito a conceitos, história, pesquisa e bibliografias sobre as Artes Visuais voltadas para o aprendizado da fotografia, além de várias práticas. Tais ações culminaram com a melhoria das nossas competência e amplitude na área de atuação. Dessarte, tornouse inevitável estabelecer relações afetivas e observacionais, em nossos encontros semanais nos quais verificamos a heterogeneidade do grupo aulista, formado por distintas classes sociais, faixas etárias, e níveis de formação.

Cada educando com sua especificidade, receptores de uma mesmo conteúdo que propiciou o descobrimento de nossas poéticas individuais. É importante ressaltar os resultados alcançados por ex-alunos, anteriores à turma da qual fazia parte, que iniciaram suas atividades artísticas no curso, uma vez que alguns ingressarem no campo da docência em fotografia contemporânea, enquanto outros foram premiados em concursos fotográficos profissionais a níveis regional, nacional e internacional.

Porém, diante da multiplicidade da fotografia enquanto fazer artístico, tendo em vista a pluralidade do alunato susodito, como ocorre o ensino e a produção da fotografia artística Paraibana através do curso FIC de extensão em Fotografia Artística do IFPB? Falamos em ensino e produção justamente porque a prática em fotografia está intrínseca ao seu aprendizado e ensinamento, nos quais técnica e poética, ou seja, o fazer fotográfico em si, se entrelaçam. Com este estudo, buscamos investigar os processos de ensino e produção em fotografia artística no estado da Paraíba, compreendendo seus processos de educação, produção, recepção e veiculação.

Ao identificarmos a questão norteadora, nosso primeiro passo foi averiguar as publicações a respeito do tema na base de dados da Biblioteca Digital Brasileira de Teses e Dissertações (BDTD) do Instituto Brasileiro de Informação em Ciências e Tecnologias (IBICT), foi quando verificamos a ausência do tema em trabalhos acadêmicos, no que diz respeito a fotografia artística na especificidade do recorte geográfico desse artigo. 
Tendo em vista, a importância do trabalho com o ensino em Artes Visuais do Instituto Federal de Educação, Ciência e Tecnologia da Paraíba - IFPB para o contexto regional e local do qual fazemos parte, esta pesquisa se torna relevante por facultar a reflexão sobre o ensino e a produção da fotografia artística na Paraíba, com o estudo de caso voltado para curso supracitado, no que tange ao tempo, ao espaço e às transformações sociais e econômicas da era contemporânea.

Consideramos pertinente esta perquirição devido o formato do curso caracterizado por ser uma Formação Inicial e Continuada que já vem demonstrando seus méritos, em nosso país, enquanto política pública educativa, transformadora e inclusiva. Ademais a função social desse estudo, oportuniza, em seu contexto, o debate público sobre ações educacionais voltadas ao ensino e aprendizado em Artes Visuais, desmistificando a identificação dos institutos federais, como sendo um conteúdo mecanicista e tecnicista. A esse respeito, basta averiguarmos os dados qualitativos e quantitativos resultantes da culminância do Encontro Nacional de Professores de Arte dos Institutos Federais (ENPAIF), que vem acontecendo já há quatro anos.

Para Martins e Tourinho (2011) as necessidades e expectativas sociais são importantes, sobretudo no tempo atual, com advento das novas tecnologias abraçadas pela educação que envolvem o visual. "Eis que a proliferação das imagens, ao mesmo tempo em que resulta as novas tecnologias, é também motivada pela combinação de demanda econômica e necessidades humanas assentadas sobre novos arranjos sociais" (MARTINS; TOURINHO, 2011, p.17).

\section{Imagem e fotografia artística em um panorama sucinto}

Produzir imagens e refletir sobre Artes Visuais, no que diz respeito suas representações pictóricas, o que ela revela e como se expõe é sobretudo ler, e atribuir significado estabelecendo relações com produções de sentido (ARGAN, 1992). A arte é o resultado em termos de materialidade da criatividade e sensibilidade humana. Ela é algo que passa a possuir uma fisicalidade e por meio de sua visualização pode ser recusada ou apreciada.

Desde a Gruta de Lascaux, até chegarmos a era contemporânea o homem vem sempre reestruturando as imagens de si mesmo. Archer (2008) nos diz que o significado da obra artística não se encontrava propriamente em seu conteúdo, às vezes surgia do contexto em que ela existia. "Tal contexto era tanto social e político quanto formal, e as questões sobre política e identidade, tanto culturais quanto pessoais" (ARCHER, 2001, p.X).

Segundo Martins e Tourinho (2011) enxergamos o mundo por meio de filtros originados por nossas trajetórias e histórias pessoais circundadas pela nossa cultura, isso inclui nossas noções formas, cores, texturas, volume, luz, movimento, etc. A maneira como reconhecemos e utilizamos essas "especificidades é mediado por relações e categorias construídas, resultantes de nossa imersão no mundo da cultura" 
(MARTINS; TOURINHO, 2011, p. 60).

A relação entre arte e cultura são indissociáveis. Desde a sua origem, a arte vem influenciando e ao mesmo tempo retratando a cultura humana em todas as suas linguagens, nas artes visuais, por meio da escultura, pintura, ou a mais recente fotografia. Segundo Argan (1992), desde sua invenção, no ano de 1839, a fotografia vem enfrentando uma dicotomia entre técnicas artística e técnicas industriais no que diz respeito as tentativas de fotografia "artística" (ARGAN, 1992, p.78).

Para esse autor citado as transformações da psicologia da visão ocasionadas pela utilização generalizada da fotografia e a produção industrial das máquinas fotográficas influenciaram profundamente o desenvolvimento das correntes artísticas visuais. Grandes funções sociais que eram do pintor passam a ser protagonizadas pelo fotógrafo como retratações e ilustrações para revistas e jornais. A fotografia passou a ser a representação fidedigna da realidade, deslocando a pintura para um nível elitizado.

Bazin (1991) sustenta que a fotografia é a ocorrência mais importante na história das artes visuais. Pois em "sua libertação e manifestação plena, a fotografia permitiu à pintura ocidental desembaraçar-se definitivamente da obsessão realista e reencontrar a sua autonomia estética" (BAZIN, 1991, p. 25).

Nos dias de hoje, as informações disponibilizadas acerca da fotografia artística provêm de diversos estudos, um dos mais completos e escolhido como referencial para nosso texto é o livro A Fotografia como Arte Contemporânea, com autoria da pesquisadora Cotton (2010) que afirma estarmos "vivendo um momento excepcional para a fotografia, pois hoje o mundo da arte a acolhe como nunca o fez e os fotógrafos consideram as galerias e os livros de arte o espaço natural para expor seu trabalho". (COTTON, 2010, p.7).

Cotton (2010) classifica a fotografia artística contemporânea em oito categorias: $1^{\text {a }}$-Fotógrafos criam estratégias, performances e eventos especialmente para a câmera, quando então realizam seus registros fotográficos. $2^{a}$ - As fotografias com narrativas de histórias construídas dentro de uma única imagem. $3^{\text {a }}$ - As fotografias "inexpressivas" que se referem a um tipo de fotografia artística marcada pela notória ausência de dramaticidade ou hipérbole visual. 4a- Fotografias de objetos e temas considerados não legítimos a priori, dentro da ótica de um léxico artístico. "Graças a um ponto de vista sensibilizado e subjetivo, tudo que há no mundo real é um tema em potencial" (COTTON, 2010, p.9).

$\mathrm{Na}$ quinta tipologia, segundo a mesma autora, fotógrafos contemporâneos agregam um estilo informal e expressivo com foco em momentos da vida cotidiana, concentrado nas relações psicológicas e pessoais, como uma espécie de diário da intimidade humana. Ainda em acordo com Cotton (2010) na sexta tipificação há fotógrafos que chegam a locais de desastre ecológico e sociais após a ocorrência da destruição, desta forma a fotografia oferece alegorias das consequências dos desatinos políticos e humanos.

Na sétima classificação, a autora susodita, aponta para fotografias que fazem 
releituras de outras obras artísticas e manifestações pictóricas a exemplo de anúncios de revista e cenas de filmes. Levando em consideração que as fotografias podem ser compreendidas enquanto procedimentos de definição cultural (COTTON, 2010, p.191). Na oitava e última classificação, segundo a estudiosa, "diversos artistas contemporâneos exploram a natureza versátil e ambígua da fotografia, usando esse meio como apenas um dos componentes de sua prática multimídia" (COTTON, 2010, p. 226).

Desta forma, compreendemos a fotografia artística como uma multiplicidade de aspectos construtivistas, a exemplo do que fora apontado por Cotton (2010). Acreditamos que outros artistas podem se hibridizar, dentre essas tipologias elencadas pela estudiosa, da mesma forma que novos olhares podem surgir, tendo em vista o avanço das tecnologias digitais no que se refere aos seus dispositivos e suportes voltados e ou apropriados por artistas e fotógrafos para a produção da fotografia enquanto expressão artística.

\section{A tradição do ensino das artes visuais em cursos de extensão na Paraíba}

Buscamos no passado reflexões que nos ajudam a entender o tempo atual, na especificidade deste estudo elencamos como protagonista comparativo o Núcleo de Arte Contemporânea NAC, tendo em vista a importância do seu pioneirismo na fruição e ensino da arte contemporânea na capital paraibana, por meio de ações de extensão universitária. Para Barbosa (2011) compreender o olhar histórico centra-se no hoje e revisita o passado pela via dos fragmentos da memória das personagens escolhidas. (BARBOSA, 2011, p.218).

Isso pode contribuir para se reinventar o presente de maneira mais reflexiva e crítica diante do desafio ensinar/aprender/ensinar arte no contexto do mundo em que vivemos, caracterizado por intensas transformações científicas, tecnológicas, políticas, artísticas e culturais. (BARBOSA, 2011, p.218).

Em acordo com Córdula (2004) a proposta de criar Núcleo de Arte Contemporânea - NAC surgiu no final da década de 70 do século passado, em ocasião de um seminário ocorrido no Museu de Arte Assis Chateaubriand, na cidade de Campina Grande na Paraíba. A propositura veio acompanhada da "ideia de núcleos de extensão e pesquisa" (CÓRDULA, 2004, p.13).

Segundo esse autor, participante ativo da implementação do núcleo, a maior preocupação foi a montagem de um modelo que contemplasse as necessidades existentes tanto no aspecto da produção de conhecimento relativo à arte contemporânea e a produção de eventos de natureza artística. Objetivando alcançar um público diferenciado dos compradores e colecionadores de arte, mas sim do que o autor classifica como "o público da arte mesmo, do fenômeno artístico como signo de conhecimento, objeto de fruição e fato cultural". (CÓRDULA, 2004, p.15).

O NAC surgia das necessidades observadas no campo artístico e cultural, ao 
mesmo tempo se voltava para a produção de textos e imagens que pudessem servir de material didático a fim de suprir as demandas dos "departamentos universitários afins e capazes também de serem publicados para subsidiar a comunidade acadêmica de informações a respeito da arte contemporânea". (CÓRDULA, 2004, p.15).

Córdula (2004, p.18) destaca a presença prestigiosa de outros importantes artistas paraibanos para as artes visuais, a saber, Antonio Dias, projetaram o NAC para o cenário nacional. Segundo esse autor foi o NAC que "anunciou, no âmbito das universidades brasileiras, a possibilidade de incorporar a arte contemporânea nos currículos, na extensão e na pesquisa". (CÓRDULA, 2004, p.20).

Segundo Gomes (2004) no que se refere a fotografia apresentada pelo NAC, o texto Roberto Pontual intitulado Tempo Fotográfico, originalmente escrito em 1980, revela-nos o núcleo tinha "todo um programa de apoio à fotografia, desde o estágio de produção em laboratório até a apresentação final ao público". (GOMES, 2004, p.94).

No caso específico do NAC, é possível verificar, historicamente, desdobramentos positivos para a cena artística e cultural paraibana no que se refere a projetos de ensino oriundos de cursos de extensão universitária pública. No que se refere a educação baseada na cultura visual Nascimento (2011), nos orienta a "compreender que o presente é impregnado pelo passado, que continua a atravessá-lo continuamente". (NASCIMENTO, 2011, p.219).

Com isso não estamos afirmando que há efetivamente uma ligação entre os dois projetos extensionistas. Mas, sim evidenciando uma tradição que se renova na cena artística, cultural que envolve o ensino e aprendizagem em arte contemporânea no estado da Paraíba.

\section{O curso FIC de Extensão em fotografia artística do IFPB}

O curso FIC de extensão em fotografia artística do Instituto Federal de Educação, Ciência e Tecnologia da Paraíba - IFPB é ofertado gratuitamente ao público interessado, no campus João Pessoa, situado no bairro de Jaguaribe. Dividido em dois módulos, o curso tem duração de dois anos.

Ressaltamos que na capital paraibana existem outros cursos voltados para área do ensino da fotografia. Tais formações, incluem uma atenção à imagem fotográfica enquanto expressão artística, porém foi verificado que apenas o curso do IFPB é ofertado de forma inteiramente gratuita e com certificação de aperfeiçoamento emitida por uma instituição de ensino federal.

Desse modo, elencamos como prioridade, para nossa investigação, a qualidade do ensino, bem como sua disponibilidade e acessibilidade, não oneroso, para um público diversificado. Justamente por acreditarmos assim como Bourdieu e Bourdieu (2006) que a fotografia é "a única prática com uma dimensão artística acessível a todos e de ser o único bem cultural universalmente consumido" (BOURDIEU; BOURDIEU, 2006, p.31). 
A metodologia utilizada são aulas expositivas dialogais, com exercício prático que envolvem um planejamento em aula, por meio de discussões coletivas, nas quais há a escolha do tema, bem como o local a ser fotografado. Também é decido o suporte das imagens e o lugar expositivo.

Essa logística de produção, imbrincada a metodologia aulista, que propicia à apresentação do material elaborado pelo discente, no decorrer do curso, em formato de exposições. Dessa forma o educando pensa as imagens e sua relação com o público.

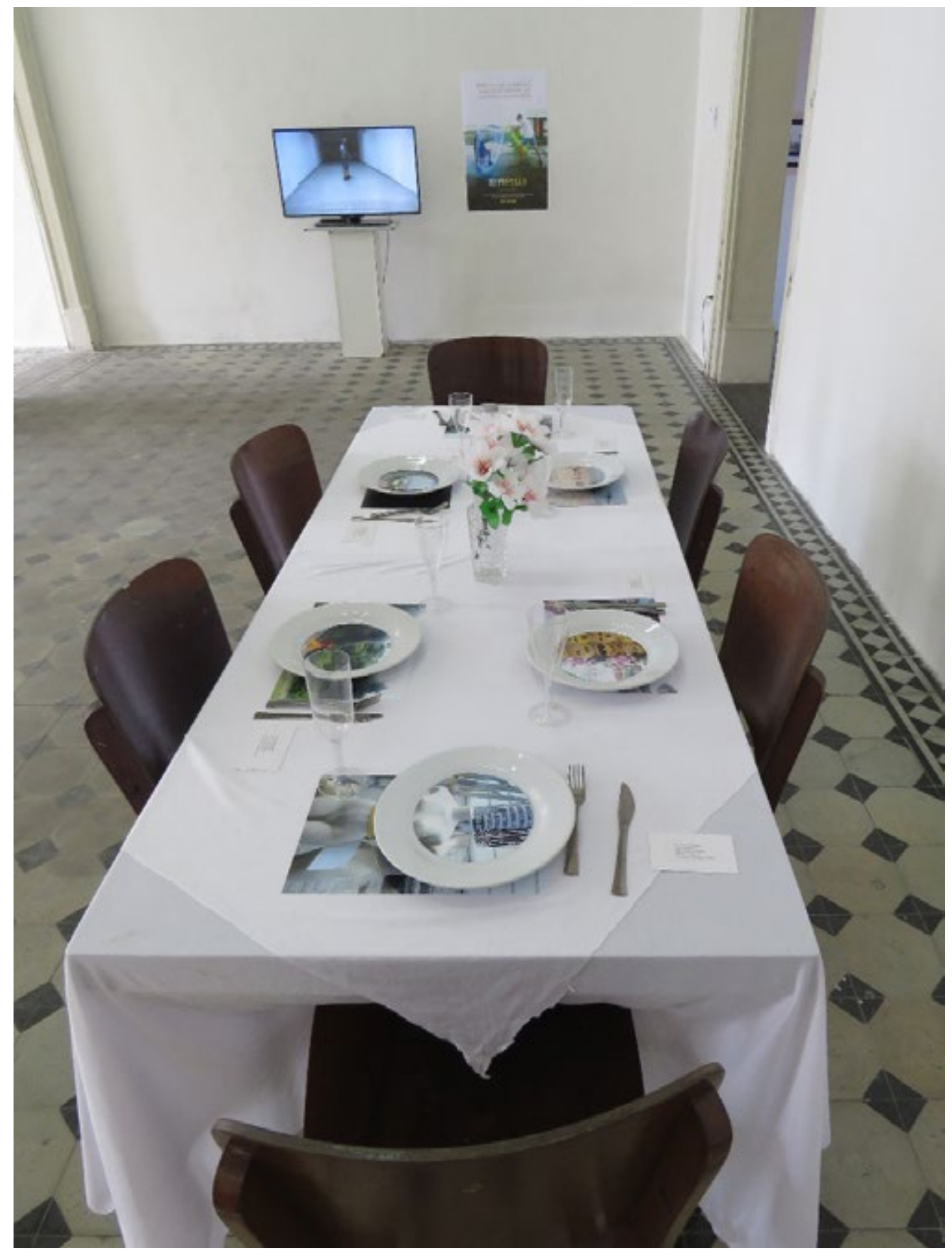

Fig. 1. Instalação famintos de Hélder Nóbrega realizada no NAC. Fonte: arquivos de Hélder Nóbrega. 
Essas exibições, inicialmente ocorrem nos espaços apropriados ou adaptados no interior da instituição pública de ensino aludida. Ressaltamos que as exposições são de natureza coletiva, e englobam todos os partícipes. Destacamos também que tais ações exibidoras ocorrem em outros lugares expositivos fora da instituição, propiciando a inserção do estudante ao mercado.

Um dos exemplos que consideramos relevantes a fim de contextualizar essas ações culturais de âmbito expositivo concomitantes ao assunto deste recorte é a experiências expositivas com a historicidade da fotografia contemporânea paraibana, por meio de uma mostra coletiva desses educandos realizada no NAC, a exemplo da instalação "Famintos" de Hélder Nóbrega com suas fotografias colocados em pratos numa mesa posta.

Outrossim se dá na preparação do aluno para a iniciação científica, no qual o curso propicia momentos de elucubrações, acerca das produções artísticas do próprio alunato com enfoque para a produção resenhas, artigos e ensaios acadêmicos, apresentados em importantes eventos científicos, a nível local e regional, subsidiados pela instituição em questão. A exemplo do Festival de Artes do IFPB ${ }^{1}$ e na Semana de Educação Ciência e Tecnologia do Instituto Federal da Paraíba².

Esses eventos ocorrem uma vez por ano e fazem parte do calendário científico do nosso estado. Verificamos que a participação dos discentes nesses eventos educacionais tem impacto em seus currículos acadêmico.

Outro ponto importante de ser mencionado está no fato dos alunos matriculados no respectivo curso não precisam ter um equipamento fotográfico pessoal. A própria instituição disponibiliza equipamentos, que fazem parte de seu acervo, para os exercícios práticos, desde que acompanhados pela docente responsável pelo curso de extensão. O que facilita o acesso das pessoas de variados níveis sociais, ao universo do ensino e aprendizagem em artes visuais, na especificidade da fotografia artística.

Mencionar o dispositivo se faz necessário devido ao amálgama que envolve o fazer fotográfico em dois âmbitos, contemplados no projeto pedagógico do referido curso. O teor técnico, ou seja, o manuseio dos equipamentos, que compreendem às escolhas de angulações, abertura do diafragma, velocidade do iso, balanço do branco, utilização da regra dos três terços, etc.

Da mesma forma, o conteúdo artístico, que consta na escolha dos assuntos a serem fotografados e seu liame com a utilização das técnicas supracitadas com a finalidade de alcançar uma poética, em termos da elaboração da imagem artística, bem como sua produção de sentidos, levando em consideração o âmbito social e cultural

1 Matéria no site do IFPB com chamada para participação de trabalhos na Semana de Artes do IFPB.

Disponível em: https://www.ifpb.edu.br/noticias/2018/10/festival-de-artes-do-ifpb-abre-inscricao-para-propostas Acesso em: 04 jan. 2020.

2 Matéria do site do IFPB relatando exposições de artes, dentre elas a atividade do curso de fotografia artística da instituição. Disponível em https://www.ifpb.edu.br/joaopessoa/noticias/2017/10/exposicoes-permanentes-dasemana-de-educacao-ciencia-e-tecnologia-estimulam-novas-formas-de-enxergar-o-cotidiano Acesso em: 06 jan. 2020 . 
no qual esses alunos junto ao curso, objetos de nosso estudo, estão inseridos. Nesse sentido, destacamos o pensamento de Brites e Tessler (2002) quando afirmam que "a peculiaridade da arte como poética não pode ser dissociada de sua compreensão mais ousada de cultura" (BRITES; TESSLER, 2002, p.80).

Todas essas ações conjuntas reverberam na formação e inclusão de novos profissionais no vasto campo de atuação do universo fotográfico. Com esse estudo verificamos que além da atuação com fotografias de natureza comercial; a exemplo das fotos de casamento e aniversário; ensaios de moda etc.; discentes que passaram pelo curso, atuam no campo do ensino de artes como professores de fotografia contemporânea, o que demonstra o impacto positivo no mercado de trabalho ocasionado pela referida formação.

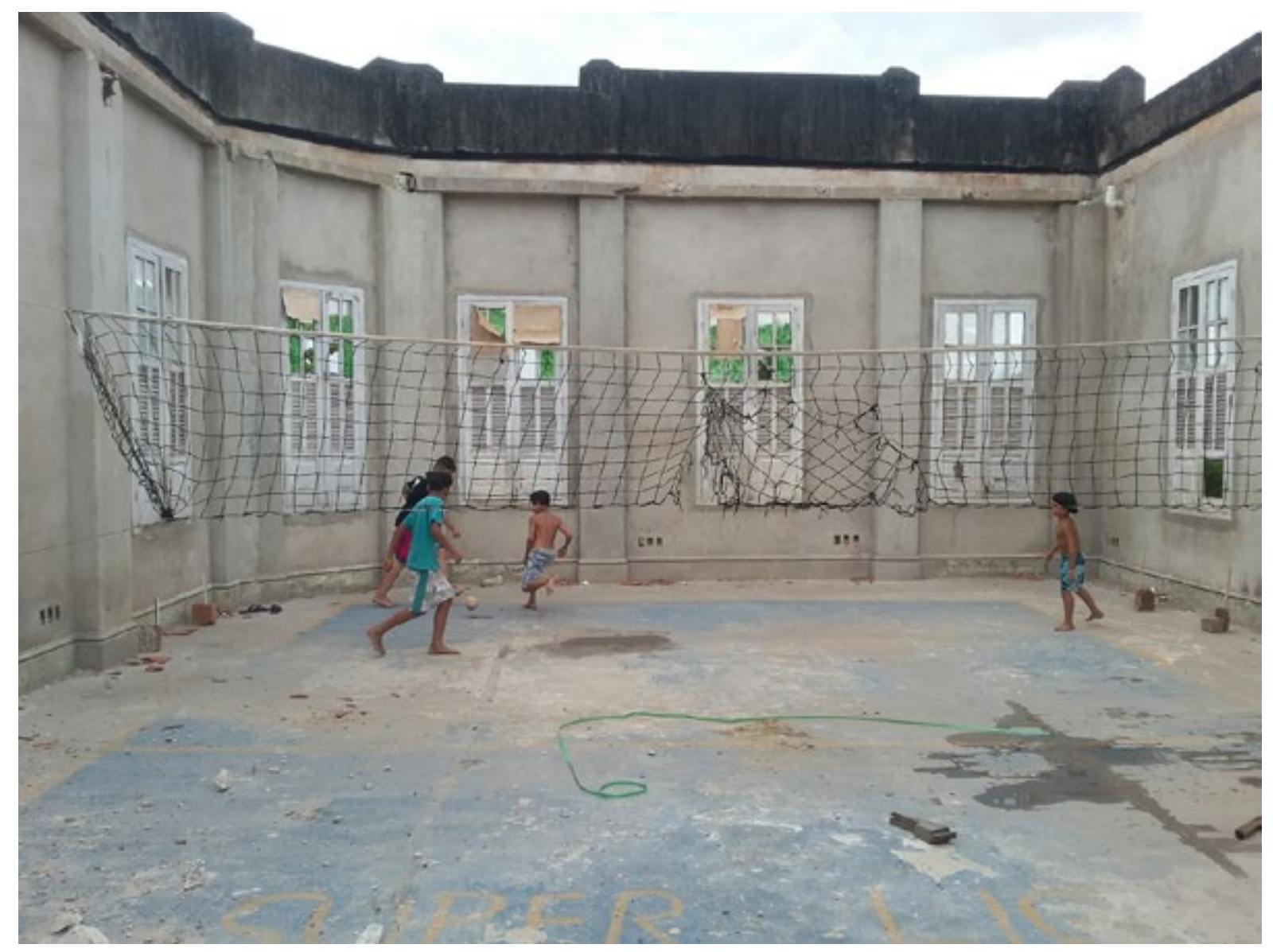

Fig. 2. "Arena" fotografia de Hélder Nóbrega. Fonte: arquivos de Hélder Nóbrega.

Concomitantes a estes fatos relatados, destacamos que houve o ingresso de exalunos ao universo das artes visuais. Educandos que conseguiram um destaque maior em exposições fotográficas a níveis local, regional, nacional e internacional. Formado pelo curso em questão, Rogério Junior ${ }^{3}$, foi premiado em concursos fotográficos de eventos a nível local como o "Mobilidade Urbana X Mercado Informal" realizado 
pelo Ministério Público da Paraíba. Em nível nacional no "VI Simpósio de Gestão e Biodiversidade (SIGABI) ", realizado pela Universidade Federal Rural do Rio de Janeiro (UFRRJ); e internacional do Festival Internacional de Fotografia - Brasília Photo Show.

Outros estudantes, tiveram fotos selecionadas para concorrerem a importantes eventos da área como o Concurso Olhares Inspiradores Canon de fotografia. A exemplo de Hélder Nóbrega, autor desse texto, com sua fotografia intitulada "Arena"4, o qual trabalha com estouros de luz em sua poética.

Com isso queremos enfatizar que o curso propicia aos seus educandos, um diálogo com o tempo atual, onde a imagem digital encontra outras possibilidades para a fluidez da fotografia artística, para outros meios de exibição, a exemplo da mídia televisiva, para além do espaço expositivo voltado para o público acostumado com a cena artística em museus ou eventos culturais similares que proporcionam exposições fotográficas.

Ademais quando se procuram por profissionais para atuarem no campo da docência em fotografia, um dos quesitos avaliadores levados em consideração pelas bancas examinadoras, são a desenvolturas do candidato com o campo artístico e profissional no que se refere a produção de sua própria fotografia, bem como a sua produtividade científica. Todas essas demandas são supridas pelo curso supracitado.

\section{Considerações finais}

método utilizado nesta pesquisa foi um estudo de caso com uma pesquisa participante. A escolha metodológica se deu prioritariamente, porque enquanto autor desse texto, já estava integrado ao curso e sendo assim familiarizado com o universo investigado, antes mesmo da ideia desta pesquisa surgir.

Desse modo, o estudo explanado foi elaborado através de minhas observações enquanto aluno participante, haja vista minha incorporação à escola o que a meu ver facilitou o desenvolvimento do processo, corroborando com meu raciocínio tenho Brandão (1981) ao estabelecer que entre os princípios gerais da pesquisa participante está o desafio de romper com as possíveis dissimetrias nas posições que envolvem as relações sociais colocadas entre perguntado e o entrevistador (BRANDÃO, 1981, p.55).

Ressaltamos que não houve gravação, nem um questionário padrão, apenas observações e alguns questionamentos pertinentes a exemplo de como uma fotógrafa, atuante na área de eventos, desenvolveu um olhar diferenciado em suas fotografias. E, em outro momento, questionamos outra aluna sobre sua inserção no campo da docência em fotografia contemporânea. Ambas associaram a concomitância entre o desenvolvimento profissional e a formação realizada no curso investigado.

4 "Arena" fotografia de Hélder Nóbrega exposta no site da Canon College Disponível em: https://college.canon. com.br/concursos/fotos/54848 Acesso em: 08 jan. 2020. 
Dessa maneira, conhecendo a estrutura física e filosófica da instituição, com o apoio do corpo discente e docente, já ciente deste projeto, fizemos a investigação, utilizando o método da pesquisa participante que segundo Gil (1991) "caracteriza-se pela interação entre pesquisadores e membros das situações investigadas" (GIL, 1991, p.55).

Todo o processo de pesquisa foi feito de forma consciente por parte de seus partícipes que verificaram na propositura investigativa uma função social relevante para a área da fotografia. Corrobora com nosso posicionamento Barbosa (2008) ao dizer que não acredita "em neutralidade na pesquisa e sim em desejo de conhecer melhor um determinado acontecimento, ou seja, contextos de sua complexidade" (BARBOSA, 2008, p.218).

A mesma estudiosa complementa o raciocínio citando Walter Benjamim em seu texto $\bigcirc$ Narrador ao dizer que o narrador tem sua marca pessoal como relator e como uma pessoa que foi diretamente envolvida nas ocorrências demonstradas.

Corroborando com nosso raciocínio trazemos também o pensamento de Brandão (1981) ao dizer que uma pesquisa participante deve ter no intermediário da investigação um tipo de pessoa que serve. Conhecedor da própria realidade, predisposto a "participar da produção deste conhecimento e tomar posse dele. Apreender a escrever a sua história de classe. Aprender a reescrever a História através da sua história". (BRANDÃO, 1981, p.11).

A vista disso, buscando uma unidade entre teoria e prática, devido ao caráter participante da investigação, procuramos estabelecer diálogos com a história e os processos de criação em fotografia artística do estado da Paraíba. Para esse feito sempre utilizando de procedimentos a fim de resguardar a confidencialidade da informação dos participantes desta pesquisa, bem como assegurar sua privacidade levando em consideração a proteção da imagem, de forma que não cause prejuízo de nenhuma natureza aos partícipes.

Compreendemos o estudo como uma configuração de sentidos que propicia enriquecer o campo investigativo sobre o ensino e a aprendizagem em Artes Visuais, na especificidade da fotografia, fornecendo informações sobre os processos de produção da hodierna fotografia artística paraibana, que dialoga diretamente com os aspectos atuais, da arte e da cultura, propiciando a formulação um pensamento histórico e crítico.

Desse modo, o estudo destaca as relações entre tradição e contemporaneidade, abordadas pelo curso no qual desenvolvem-se trabalhos e pesquisas em fotografia, contemplando os meios tecnológicos e digitais, em processos híbridos, que em seu teor criativo envolvem uma ampla gama de possibilidades, estreitando as relações entre os suportes mais tradicionais e os mais expandidos, a exemplo das exibições subsidiadas em sites da web.

Quando observamos o ensino da fotografia voltada para diversos públicos, com seus resultados expressivos para o desenvolvimento profissional dos indivíduos, no que compete seus processos de produção tanto em imagens poéticas e artística quando as de natureza mais tecnicistas como as fotografias profissionais realizadas em eventos verificamos um status quo ao curso aludido. 
Além de sua contribuição para o entendimento dos processos de ensino e fluidez em fotografia artística, no estado da Paraíba, acredito que esse trabalho embrionário será frutífero e capaz de servir como base para outros futuros estudos. Ademais, intrínseco ao texto consta um relato no qual evidenciamos uma demanda verificada acerca de uma pós-graduação lato sensu, na área da fotografia no estado da Paraíba, assunto que pode também ser pautado, com novos enfoques, por outras pesquisas vindouras.

\section{Referências}

ARCHER, Michael. Arte Contemporânea: uma história concisa. São Paulo: Martins Fontes, 2008.

ARGAN, Giulio Carlo. Arte moderna. São Paulo: Companhia das Letras. 1992.

BARBOSA, Ana Mae (Org.). Ensino da Arte: memória e história. São Paulo: Perspectiva, 2008.

BAZIN, André. O cinema ensaios. São Paulo: Editora Brasilienese, 1991.

BOURDIEU, Pierre e BOURDIEU, Marie-Claire. O Camponês e a Fotografia. Curitiba: Revista Sociologia e Política, 2006.

BRANDÃO, Carlos Rodrigues (Org.). Pesquisa participante. São Paulo: Editora Brasiliense, 1981.

BRITES, Blanca; TESSLER, Élida. O meio como ponto zero: metodologia da pesquisa em artes visuais. Porto Alegre: Editora da UFRGS, 2002.

COTTON, Charlotte. A fotografia como arte contemporânea. Tradução Maria Silva Mourão Netto, Marcelo Brandão Cipolla. 2 ed. São Paulo: Editora WMF Martins Fontes, 2013.

GIL, Antônio Carlos. Como elaborar projetos de pesquisa. São Paulo: Atlas, 1991.

MARTINS, Raimundo; TOURINHO, Irene. Educação da Cultura Visual: conceitos e contextos. Santa Maria: Editora da UFSM, 2011.

NASCIMENTO, Erinaldo Alves do. Singularidades da educação da cultura visual nos deslocamentos das imagens e das interpretações. In: MARTINS, Raimundo; TOURINHO, Irene (Orgs.) Educação da Cultura Visual: conceitos e contextos. Santa Maria: Editora UFSM, 2011.p. 209-226. 